\title{
Bringing cognitive testing into the real world
}

Elizabeth Coulthard and Masud Husain

J. Neurol. Neurosurg. Psychiatry 2008;79;363-

doi:10.1136/jnnp.2007.139832

Updated information and services can be found at:

http://jnnp.bmj.com/cgi/content/full/79/4/363

These include:

References This article cites 6 articles, 4 of which can be accessed free at:

http://jnnp.bmj.com/cgi/content/full/79/4/363\#BIBL

Rapid responses You can respond to this article at:

http://jnnp.bmj.com/cgi/eletter-submit/79/4/363

Email alerting Receive free email alerts when new articles cite this article - sign up in the box at service the top right corner of the article

Notes

To order reprints of this article go to:

http://journals.bmj.com/cgi/reprintform

To subscribe to Journal of Neurology, Neurosurgery, and Psychiatry go to:

http://journals.bmj.com/subscriptions/ 


\section{Bringing cognitive testing into the real world}

\section{Elizabeth Coulthard, Masud Husain}

Imagine a world without neuropsychologists. "Would we notice?", some might remark. That's because many clinicians erroneously believe that cognitive tests have little to offer either the neurologist or their patient. Increasingly, however, neuropsychology is moving from the apparently esoteric world of complex, pen-andpaper test batteries into the everyday lives of patients. For example, frontal patients may pass standard tasks of "executive function", but nevertheless have marked deficits in planning, organisation and multitasking that can be revealed by a multiple errands task that probes their ability to shop effectively! In this issue, Punt and colleagues $^{2}$ (see page 464) examine another real-world issue: the problems encountered by stroke patients with unilateral neglect when operating a wheelchair.

These authors investigated the everyday relevance of a previous pen-and-paper finding-the "cross-over effect"-to patients with neglect trying to navigate around or between obstacles. The crossover effect describes the tendency of neglect patients to bisect a long line towards their ipsilesional (good) side but curiously bisecting a short line towards their contralesional (neglected) side. $^{3}$ Remarkably, Punt and colleagues replicate the seemingly paradoxical cross-over effect in their wheelchair experiment.

Institute of Neurology \& Institute of Cognitive Neuroscience, UCL, National Hospital for Neurology \& Neurosurgery, London, UK

Correspondence to: Professor M Husain, Institute of Neurology \& Institute of Cognitive Neuroscience, UCL, National Hospital for Neurology \& Neurosurgery, London WC1N 3BG, UK; m.husain@ion.ucl.ac.uk
When their patients negotiated large gaps in their wheelchairs, they deviated towards their ipsilesional side, but when they attempted to steer through small gaps, they tended to steer contralesionally, towards their neglected side. In fact, when asked to pass through small apertures, neglect patients were far more likely to have collisions on their neglected side than on the opposite side. Importantly, the authors point out that their patients maintained a relatively constant distance from the right boundary, regardless of gap size, suggesting that they paid more attention to the ipsilesional side of an opening.

These findings from a real-world, clinical problem echo those from recent experimental studies showing that the pattern of line bisection in neglect patients may best be attributed to weighting of the ipsilesional end of line significantly more than its contralesional counterpart. ${ }^{4}$ This might be because the endpoint of a line on the "good" side of space wins in the competition for visual selection over the opposite endpoint, or because patients are unable to represent the contralesional endpoint accurately due to difficulties in keeping track of spatial locations. ${ }^{5}$ A new experimental study suggests that such spatial working memory deficits for maintaining leftward locations might be particularly prominent after rightward eye movements. ${ }^{6}$

It is easy to see how these findings from experimental cognitive neuroscience and observations of wheelchair navigationwhen combined-might be applied directly to improving awareness of the problems encountered by people with neglect. They might even suggest techniques for improving behavioural therapies, such as teaching patients first to gaze at the right end of a doorway and then the left, before attempting to steer through it. Second, this simple paradigm could be used in further work investigating the relationship between experimental deficits and functional impairment. A third and perhaps less obvious benefit of the approach taken by Punt and colleagues is that we are beginning to realise just how much the way in which our brains perform cognitive operations is critically dependent on context. Our sensory and spatial systems do not operate in isolation from motor, intentional or "executive" processes. The way in which a task is framed, the testing environment or even just the knowledge of being tested may alter the way in which a patient performs a task. These insights are crucial if we are to make the most of neuropsychology in solving problems encountered by patients in everyday situations.

\section{Competing interests: None declared.}

J Neurol Neurosurg Psychiatry 2008;79:363. doi:10.1136/jnnp.2007.139832

\section{REFERENCES}

1. Alderman N, Burgess PW, Knight $\mathrm{C}$, et al. Ecological validity of a simplified version of the multiple errands shopping test. $J$ Int Neuropsychol Soc 2003;9:31-44.

2. Punt TD, Kitadono K, Hulleman J, et al. From both sides now: crossover effects influence navigation in patients with unilateral neglect. J Neurol Neurosurg Psychiatry 2008;79:464-6.

3. Doricchi F, Guariglia P, Figliozzi F, et al. Causes of cross-over in unilateral neglect: between-group comparisons, within-patient dissociations and eye movements. Brain 2005;128:1386-406.

4. McIntosh RD, Schindler I, Birchall D, et al. Weights and measures: a new look at bisection behaviour in neglect. Brain Res Cogn Brain Res 2005;25:833-50.

5. Mannan SK, Mort DJ, Hodgson TL, et al. Revisiting previously searched locations in visual neglect: role of right parietal and frontal lesions in misjudging old locations as new. J Cogn Neurosci 2005;17:340-54.

6. Vuilleumier $\mathbf{P}$, Sergent C, Schwartz S, et al. Impaired perceptual memory of locations across gaze-shifts in patients with unilateral spatial neglect. J Cogn Neurosci 2007;19:1388-406. 